\title{
Zuurstofsaturatie meten met een smartphone
}

Ward Seuntjens, Joris Schollaert, Ardavan Kashtiara, Wouter Platteau, Josefien van Olmen

Vanwege de verspreiding van het SARS-CoV-2-virus is het voor huisartsen momenteel niet zo eenvoudig om de zuurstofsaturatie bij patiënten te meten. Patiënten kunnen echter ook thuis de zuurstofsaturatie meten met een pulse oximeter of smartphoneapp. Wij vroegen ons af of saturatiemetingen met een smartphone, aan de hand van de smartphone-LED en -camera, bruikbaar zijn voor de medische praktijk. Deze meetmethode blijkt helaas nog niet betrouwbaar.

Het lijkt voor de hand te liggen: veel mensen hebben een smartphone en zouden deze kunnen gebruiken om zuurstofsaturatie te meten. Het onderliggende mechanisme van camera-oximetrie met een smartphone is vergelijkbaar met pulse oximetrie met de welbekende fingertip oximeter. Een lichtbron, in dit geval de LED-flash van de smartphone, verlicht met afwisselende golflengtes de geperfundeerde weefsels met een gekend lichtspectrum. De smartphonecamera fungeert als detector en onderscheidt de fotonen die door het weefsel passeren en niet worden geabsorbeerd of verspreid [figuur 1]., ${ }^{1,2}$

\section{ONDERZOEKSMETHODE}

Bij ons onderzoek hanteerden wij de PICO-methode:

Patiënt Iedere patiënt die thuis zijn zuurstofsaturatie wil meten

Interventie Gebruik van een app op een mobiele telefoon

Controle Een fingertip oximeter of arteriële bloedgaswaarden

Outcome Accurate meting van de zuurstofsaturatie in het perifere bloed

Figuur 1

Typische opstelling voor contactfoto-plethysmografie. De vinger wordt op de camera van de smartphone geplaatst en belicht door het ingebouwde LED-lampje. Fotonen met een langere optische weglengte $[A]$ worden sterker afgezwakt dan fotonen met een kortere optische weglengte [B]

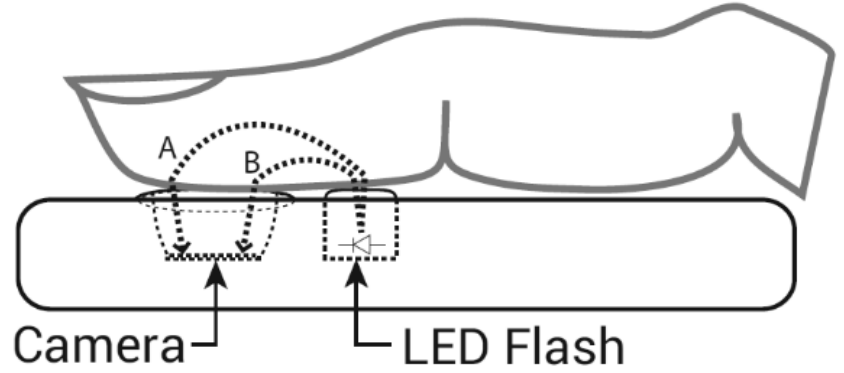

Bron: Karlen W, et al.

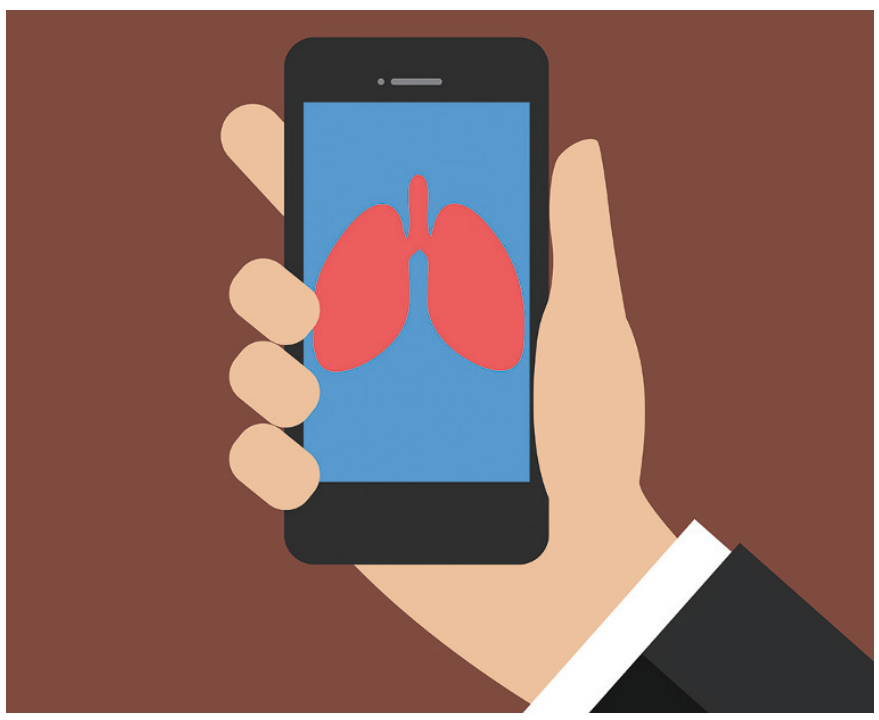

Smartphoneapplicaties zijn op dit moment nog niet geschikt om zuurstofsaturatie te meten.

Foto: Shutterstock

Op 8 april 2020 voerden we de volgende zoekopdracht uit in PubMed: (“Oximetry”[Mesh] OR "Blood Gas Monitoring, Transcutaneous"[Mesh]) AND (“Telemedicine”[Mesh] OR “Smartphone"[Mesh] OR “Telephone”[Mesh]).

We includeerden onderzoeken over saturatiemeting door middel van smartphoneapplicaties met controlemeldingen aan de hand van een fingertip oximeter of arteriële bloedgaswaarden. We excludeerden artikelen als de volledige tekst ontbrak, wanneer de smartphone externe sensoren gebruikte of bij een andere taal dan Engels of Nederlands. De zoekopdracht resulteerde in 83 artikelen, waarvan er na het toepassen van de inclusie- en exclusiecriteria 5 artikelen overbleven. ${ }^{3-7}$ Daarnaast vonden we een expert opinion van Tarassenko en Greenhalgh van het Oxford COVID-19 Evidence Service Team op de website van het Centre for Evidence-Based Medicine. ${ }^{2}$

\section{RESULTATEN}

Tayfur et al. maten de saturatie van 101 volwassen patiënten op de spoedeisende hulp. ${ }^{3}$ Ze vergeleken hierbij de metingen van de Samsung Health Application (Galaxy S8) met arteriële bloedgaswaarden. Hun onderzoek toonde bij saturaties hoger dan $93 \%$ een goede correlatie aan tussen een saturatiemeting met de smartphone en arteriële bloedgaswaarden. Bij saturaties lager dan 93\% waren er echter opvallende verschillen tussen de saturatiemeting met de smartphone en arteriële bloedgaswaarden [online figuur 2]. De betrouwbaarheid van de app was dus laag bij lage saturaties.

Tomlinson et al. voerden een klinische trial uit bij 81 gezonde kinderen. ${ }^{4} \mathrm{Zij}$ vergeleken de zuurstofsaturatiemeting van 
een smartphoneapp die alleen de interne hardware (camera) gebruikt met een smartphoneapp die externe hardware gebruikt (een saturatiemeter die kan worden aangesloten). De camera-based app bleek volgens de auteurs niet inferieur aan de externe hardware. Er zaten echter alleen kinderen met een saturatie boven de $97 \%$ in de trial.

Alexander et al. concludeerden in hun klinische trial met 100 gezonde deelnemers een gebrek aan correlatie tussen de saturatiemeting met de smartphoneapplicatie en de fingertip oximeter (intrabeoordelaarsbetrouwbaarheid tussen de 0,188 en 0,239$).{ }^{5}$ Ze wijzen op mogelijk gevaar voor de patiënt bij het gebruik van deze applicaties. Het dramatische scenario zou zich kunnen voltrekken dat een patiënt met een gedaalde saturatie met zijn smartphone een fout-normale waarde meet en daardoor geen verdere actie onderneemt.

Door nieuwe technologieën probeert men de betrouwbaarheid van saturatiemeting met een smartphoneapplicatie te vergroten. Zo voerden Ding et al. een klinische trial uit met 39 gezonde deelnemers. ${ }^{6}$ Ze bepaalden de saturatie via convolutionele neurale netwerken in smartphones met een medische pulse oximeter als controle. Zij concludeerden dat de onderzochte technologie betrouwbaar zou zijn, maar dat vervolgonderzoek nodig is om de bruikbaarheid vast te stellen. Scully et al. deden een klinische trial met een onbekend aantal deelnemers, waarbij ze saturatiemeting met een smartphone op basis van de blauw/rood-ratio vergeleken met een medische pulse oximeter. ${ }^{7}$ De smartphone was accuraat bij het meten van saturatiefluctuaties. Of de exacte saturatie betrouwbaar kan worden gemeten moet nog verder worden onderzocht. De experts van de Universiteit van Oxford bespreken het belangrijkste technische probleem bij smartphones. ${ }^{2}$ Saturatiemeting met een smartphone werkt evenals een fingertip oximeter met een lichtbron met alternerende golflengte. De tekortkoming van een smartphone is dat de ingebouwde camera het verschil in golflengte van de reflectie niet nauwkeurig kan onderscheiden. Dit maakt betrouwbare metingen momenteel onmogelijk. Zie voor een overzicht ook de [online evidentietabel].

\section{KANTTEKENINGEN}

De onderzoekers van de geselecteerde artikelen zijn over het algemeen optimistisch over het concept, met uitzondering van Alexander et al. ${ }^{5}$ De gevonden onderzoeken bevatten echter diverse methodologische tekortkomingen. De onderzoekspopulatie bestond veelal uit gezonde personen, terwijl accurate saturatiemeting juist belangrijk is bij mensen met respiratoire klachten., ${ }^{3,6}$ Verscheidene onderzoeken wijzen daarom op de noodzaak van verder onderzoek. ${ }^{3,6,7}$

Het onderzoek van Tayfur et al. betrof wel patiënten die zich op de spoedafdeling presenteerden. Zij includeerden daardoor ook patiënten die een lagere saturatie hadden dan normaal (gemiddeld so2 met ABG 94,02\%; SD 3,738). ${ }^{3}$

Bij de onderzoeken van Ding et al. en Scully et al. is er risico op confirmation bias. ${ }^{6,7}$ Hoewel de onderzoekers een grote expertise op dit gebied hebben, hebben zij mogelijk ook belang bij het welslagen van het concept van saturatiemetingen met smartphoneapplicaties, omdat zijzelf gezondheidsapps ontwikkelen. De experts van het Oxford COVID-19-team stellen vast dat er methodologische fouten zitten in de onderzoeken van Tayfur en Tomlinson. ${ }^{2}$ Zij zijn daarom minder optimistisch over de huidige toepassingen van de smartphone. Bij het onderzoek van Tayfur et al. stellen de experts als voornaamste probleem dat de gebruikte opstelling accurate metingen onmogelijk maakt: de Samsung Galaxy S8 gebruikt namelijk een LED waarvan de golflengte niet kan wisselen. Licht met wisselende golflengte vormt echter de basis voor saturatiemeting. Verder noemen ook de experts de eerder vermelde afwijkende saturatiemetingen bij lagere saturaties. ${ }^{2,3} \mathrm{Bij}$ het onderzoek van Tomlinson et al. is de gebruikte maat voor accuraatheid onduidelijk. De auteurs stellen dat de Digidoc app binnen een saturatiebereik van 90 tot $100 \%$ kan meten met een accuraatheid van 0 tot 4 'RSM' in vergelijking met een pulse oximeter. ${ }^{4}$ Tarassenko en Greenhalgh veronderstellen dat een RMSE (root-mean-square error) van $4 \%$ wordt bedoeld. Dit zou betekenen dat bij een saturatie van 95\% de Digidoc app waarden zou weergeven die variëren van 91 tot $99 \%$. De Digidoc app is daarom niet betrouwbaar. ${ }^{2}$

\section{CONCLUSIE}

Smartphoneapplicaties zijn op dit moment nog niet geschikt om zuurstofsaturatie te meten. Er is geen commercieel verkrijgbare applicatie voor smartphones die zonder externe sensor op een betrouwbare manier zuurstofsaturatie kan vaststellen. Vooral bij lage zuurstofsaturatie blijken de apps onbetrouwbaar. Het is aan te raden deze applicaties, zonder een externe sensor, niet te promoten bij patiënten als een betrouwbare meetmethode.

\section{LITERATUUR}

1. Karlen W, Ansermino JM, Dumont GA, Scheffer C. Detection of the optimal region of interest for camera oximetry. Conference proceedings: Annual International Conference of the IEEE Engineering in Medicine and Biology Society IEEE Engineering in Medicine and Biology Society Annual Conference 2013;2013:2263-6.

2. Tarassenko L, Greenhalgh T. Question: Should smartphone apps be used as oximeters? Oxford: Centre for Evidence-Based Medicine, 2020.

3. Tayfur I, Afacan MA. Reliability of smartphone measurements of vital parameters. A prospective study using a reference method. Am J Emerg Med 2019;37:1527-30.

De volledige literatuurlijst vindt u bij dit artikel op www.henw.org.

Seuntjens W, Schollaert J, Kashtiara A, Platteau W, Van Olmen J. Zuurstofsaturatie meten met een smartphone. Huisarts Wet 2020;63[8]:64-5. D0I:10.007/ s12445-020-0803-6.

Universiteit Antwerpen, Faculteit Geneeskunde en Gezondheidswetenschap pen, België: W. Seuntjens, student geneeskunde, ward.seuntjens@student. uantwerpen.be; J. Schollaert, student geneeskunde; A. Kashtiara, student geneeskunde; W. Platteau, student geneeskunde; prof. dr. J. van Olmen, hoogleraar huisartsgeneeskunde, tevens Centrum voor Huisartsgeneeskunde, vakgroep ELIZA, Faculteit Geneeskunde en Gezondheidswetenschappen, Universiteit Antwerpen, België.

Mogelijke belangenverstrengeling: niets aangegeven.

Dit is een critically appraised topic [CAT], waarbij de auteur een evidence based antwoord wil krijgen op een praktijkvraag. 